\title{
Understanding how students perceive the role of ideas for their knowledge work in a knowledge-building environment
}

\author{
Huang-Yao Hong and Chieh-Hsin Chiu \\ National Chengchi University, Taiwan
}

\begin{abstract}
This study explored how students viewed the role of ideas for knowledge work and how such view was related to their inquiry activities. Data mainly came from students' online interaction logs, group discussion and inquiry, and a survey concerning the role of ideas for knowledge work. The findings suggest that knowledge building was conducive to developing among students a more informed view of ideas that sees ideas as improvable, real-world objects for collaborative and creative knowledge work, rather than merely as abstract thoughts for achieving an individual's own knowledge acquisition. Moreover, it was found that how a group views the role of ideas was associated with how they improve the quality of the ideas during their group inquiry.
\end{abstract}

\section{Introduction}

As argued by Reigeluth (2013), the educational paradigm before the 21st century was based on an industrial model in which standardisation and the mass production of manufacturing is highly valued. Under this paradigm, educational practice tends to highlight efficiency of individual knowledge acquisition and accumulation by teaching learners the same content and skills that are predetermined by strict curriculum guidelines under a precise time frame (e.g., see Adams \& Engelmann, 1996; Magliaro, Lockee, \& Burton, 2005). Within such instructional practices, students are seldom given opportunities and autonomy to engage in self-directed inquiry that requires them to produce and continuously improve their ideas for knowledge work. However, given the rise of an information-driven and knowledge-based society (UNESCO, 2005), the industrial age-based educational paradigm is gradually giving way to a new economic model that favours customisation and a personalised information service (Reigeluth, 2013). As such, conventional educational practice is also shifting to focus more on cultivating competent and creative citizens who are able to work creatively and collaboratively with ideas for solving urgent environmental and social issues in service of the public good (Florida, 2002). This is in sharp contrast to traditional teaching in which ideas are often viewed as irrelevant and disruptive thoughts that interfere with the pre-specified teaching plan and classroom routines. Students with innovative ideas in class are sometimes even treated as unruly and misbehaved learners. Unsolicited ideas are especially highly unwelcome as they forbid teachers from completing their deliberate instructional goal and their assigned responsibilities for covering more curriculum materials in less time (Papert, 2000). Papert (2000) described such a situation that is commonly observed in most traditional learning environments as "idea aversion" (i.e., dislike of ideas). Inculcated with such a deep-rooted belief, it is unlikely for students to be given any chances of producing their own ideas and working innovatively with these ideas for collective knowledge advancement. It is also impossible for students to learn to appreciate the importance of ideas for creating new knowledge and solving real-world problems.

The aim of this study was to improve understanding of how to foster students' capacity to work collaboratively and innovatively with ideas and to help them develop a more informed view of the role of ideas for their knowledge work. The two research questions concerned in this study are (1) whether engaging students in knowledge building would help them enhance their online performance by working more cohesively as groups while collaboratively achieving their groups' knowledge work and (2) whether students who are more engaged in knowledge-building activities would also be more likely to develop a more informed view that sees ideas as essential objects for sustained knowledge work.

\section{Literature review}

\section{Fostering a design-mode of view for sustained idea improvement}

One way to help students develop a deeper understanding and appreciation of “ideas" as essential objects for knowledge creation may be to engage students in actual "knowledge-building” activities (Hargreaves, 1999; Hong \& Sullivan, 2009; Scardamalia \& Bereiter, 2006). Knowledge building is defined as a 
collaborative process focused on sustained production and improvement of ideas in a community (Bereiter \& Scardamalia, 2003). As an idea-centred pedagogical approach, knowledge building draws on Popper's (1972, 1978) three-world epistemological position of constructivism. In addition to the physical/material world (world 1) and the psychological world existing in the human mind (world 2), Popper posited a world 3 reality that is mainly constituted of ideas. These ideas are produced by knowledge workers (e.g., engineers, scientists, designers, and architects), and, once created, they are embodied within a social life like tangible, real-world objects that can be further tinkered and experimented with by other knowledge agents and become more powerful solutions to problems. Under a world 3 view, therefore, ideas should be treated as tentative knowledge claims and be continuously subjected to critical scrutiny (e.g., through examination, clarification, and falsification) for further development. Likewise, in order to develop a successful knowledge-building community, its members also need to perceive the role of ideas as world 3 improvable objects for collective knowledge advancement (Scardamalia, 2002), rather than merely treating them as world 2 psychological constructs for achieving personal knowledge gain. Unfortunately, as cogently argued by Bereiter (1994), conventional classroom teaching tends to focus on instilling in students' minds a prescribed body of knowledge from a world 2 perspective, while neglecting the importance of cultivating students' competencies to work with ideas in world 3.

To address this concern, it is important to distinguish two different modes of knowledge work: belief mode and design mode (Bereiter, 2002; Bereiter \& Scardamalia, 2003). To elaborate, the belief mode emphasises the ability to evaluate ideas and/or knowledge claims using well-established and accepted true beliefs. Students' intellectual life and classroom work in schools is conventionally dominated by such a mode of thinking. When students' minds are functioning in a belief mode, they are often guided to ponder questions such as: Is this idea true or reasonable? What are the assumptions on which this idea is based? In contrast, the design mode of thinking highlights the ability to go beyond the pursuit of truth by engaging in sustained idea generation and improvement for knowledge advancement. When students are committed to a design mode of knowledge work, they tend to ask questions such as: What is the value of this idea? What is it good for? What can it or can it not do? How can it be further improved? While both modes are needed for knowledge work, a main epistemological difference between the two modes of view is that the belief mode tends to highlight knowledge acquisition and accumulation by viewing ideas as knowledge claims to be verified; whereas the design mode intends to facilitate innovative knowledge work by viewing ideas as improvable objects for knowledge advances (Cross, 2007).

One important thing to note is that engaging in a design-mode of knowledge work is, in essence, a metacognitive process, as one has to constantly reflect and plan ahead in order to continually advance ideas. Particularly from the perspective of knowledge building as a social process, the kind of metacognitive behaviours required for design-mode activities must be collectively (rather than individually) attained. How a knowledge-building group sees the role of ideas and accordingly exercises its self-regulatory efforts can greatly influence the effectiveness of their knowledge advancement activities (Hong \& Sullivan, 2009). Previous studies have also shown that productive collaborative knowledge work is greatly related to a group's regulation activities (e.g., Dehler, Bodemer, Buder, \& Hesse, 2011; Goos, Galbraith, \& Renshaw, 2002).

\section{Fostering the process of idea improvement}

Hong and Sullivan (2009) proposed an idea-centred instructional framework to illustrate the collaborative, emergent, and self-regulated process of sustained idea improvement in a typical knowledge-building environment. This framework illustrates "idea generation”, "idea diversification”, and "idea elaboration" as three important activities for the process of effective idea improvement.

First, in terms of idea generation, most research literature has considered it as an essential phase for productive knowledge or design work (e.g., Linsey et al., 2011), and an important line of empirical research has investigated effective instructional strategies or techniques to help idea generation (Faure, 2004; Miura \& Hida, 2004; Mumford, 2001; Paulus \& Yang, 2000; Rietzschel, Nijstad, \& Stroebe, 2014). For example, Rietzschel et al.'s (2014) study found that when students were guided to work in a more narrowed (as contrasted with more broad) problem scope or when they were required to come up with ideas that were more original (as contrasted with more relevant), they were more likely to come up with innovative ideas. Hong, Chang, and Chai's (2011) study found that it is more likely to foster idea 
generation when students are allowed to work on problems of their own interest and when the learning climate in an environment is perceived by learners as more open and creative.

Second, from a socio-epistemological perspective (Fuller, 1988), idea diversification can be achieved by means of exchanging ideas or perspectives among members with distributed expertise. Previous research has suggested that idea exchange is critical to the process of knowledge advancement (Gong, Kim, Zhu, \& Lee, 2013; Hong, Scardamalia, \& Zhang, 2010; Perttula, Krause, \& Sipilä, 2006). For example, Perttula et al.'s (2006) design experiment found that individuals who exchanged ideas were more likely to generate more ideas. Kohn, Paulus, and Choi (2011) conducted two experiments to explore the knowledge sharing process during which ideas are exchanged and/or combined in students' brainstorming activities. They found that group endeavour was more effective than individual effort in generating more novel and viable idea combinations.

Thirdly, from the perspective of evolutionary epistemology (Popper, 1978), ideas can be refined by community members acting as knowledge workers reflecting collaboratively on the potentials and limitations of the ideas at issue. Previous studies have investigated ways of collaboration to help further elaborate ideas (e.g., Chen, Chuy, Resendes, Scardamalia, \& Bereiter, 2011; Kipp, Bittner, Bretschneider, \& Marco, 2014) and ways of idea elaboration that may enhance or hinder creative knowledge work (e.g., Kudrowitz \& Wallace, 2013; Stark \& Perfect, 2008; Verhaegen, Vandevenne, Peeters, \& Duflou, 2013). For example, Kudrowitz and Wallace's (2013) study found that the systematic use of a metric integrating three attributes (i.e., novelty, usefulness, and feasibility) as an elaboration means can be helpful in identifying more innovative ideas.

In a productive idea improvement process, once the initial ideas are generated, they need to be reified (e.g., presented as a note or a message and contributed to an online database). Doing so helps transform these initial ideas from an individual's mental constructs to become public property recorded permanently (e.g., in an online database). This is important as ideas conceived only in one's mind (as world 2) cannot be treated as tangible objects for collective improvement. Further, the extent of idea diversification and exchange is a function of how ideas beget more ideas and interact with and relate to one another; and idea reflection or elaboration is a function of how collaborative knowledge workers try to increase the value of ideas and deepen their collective understanding of what the ideas can or cannot do to address the problem they are dealing with. In an optimal situation, idea improvement relies on an emerging process of idea generation, with idea diversification and idea elaboration serving as two essential social mechanisms closely intertwined to enable the transformation of initial ideas into more innovative ones (Chen, Scardamalia, Acosta, Resendes, \& Kici, 2013).

\section{Assessing ideas as outcomes of idea improvement}

Along with an emerging knowledge-building process, ideas are expected to be transformed into tentative learning outcomes, including (1) initial ideas that are generated and contributed individually to a community's database, (2) diversified ideas that are made possible through sharing/exchanging of or relating to the initial ideas, to (3) elaborated ideas that are further refined or modified continually by means of collaborative reflection among community members, and (4) more promising and valuable ideas that are made possible from opportunistically integrating diversified and elaborated ideas into more feasible solutions or coherent accounts for addressing a problem. When ideas as outcomes transformed from an emergent improvement process are to be treated as real-world material objects, it is likely for a knowledge-building group or class to form a complex collection of ideas (recorded in a database) that emulates a knowledge community or what Popper (1978) called world 3 reality.

Through gradually improved ideas as tentative outcomes at different knowledge-building phases, it is expected that students would gradually work out more valuable, feasible ideas. So, the next relevant question to ask is whether such idea-improvement activities would eventually produce more quality ideas that are useful to a community for solving the problems concerned. One way to improve the quality of ideas is perhaps to increase the quantity of ideas. As suggested in Osborn's (1953) research regarding idea evaluation, quality ideas are more likely to be produced if an adequate number of ideas can be generated first. In other words, quantity of ideas represents an effective measure of quality of ideas. However, other studies (e.g., Connolly, Jessup, \& Valacich, 1990; Graham, 1977; MacCrimmon \& Wagner, 1994) also found that the correlation between quality and quantity is often thin or insignificant 
and sometimes even negative. Given this controversy, it would be appropriate to directly measure the quality of ideas itself as a way of assessing the outcome of idea improvement at the latter knowledgebuilding phase. As world 3 objects, the ideas worked on in a knowledge-building community are already reified and recorded in an online database, idea improvement can therefore be focused on identifying progressively more innovative ideas posted on the Knowledge Forum (i.e., whether an idea is able to solve a problem, address an issue, or design a better product) (Chen et al., 2013). Specifically related to the design of technological products, more innovative ideas are ideas that can make a product become more useful in people's daily lives. For example, Brown (2009) offered a set of criteria to assess the quality of ideas, using feasibility, viability, and desirability. Dean, Hender, Rodgers, and Santanen (2006) developed the scales for idea evaluation in which the following criteria are employed, including novelty, "the degree to which an idea is original"; workability, "an idea is workable (feasible) if it can be easily implemented and does not violate known constraints"; relevance, "[an] idea applies to the stated problem and will be effective at solving the problem"; specificity, "an idea is specific if it is clear (worked out in detail)” (p. 663). With proper assessment, community members will be more likely to eventually produce valuable and promising ideas and to assume the collaborative responsibility of idea improvement for the overall advancement of knowledge in their community (Scardamalia, 2002).

\section{The present study}

In the present study, we investigated the quantity and quality of how students worked innovatively with ideas as improvable objects and how such improvement were related to how they perceived the role of ideas during their knowledge-building process.

Previous empirical studies on students' knowledge-building activities have been mainly focusing on exploring effective implementation of instructional strategies and design of technological tools to improve student learning in different subject areas (e.g., Hong, Chai, \& Tsai, 2015; Hong, \& Scardamalia, 2014; Lee, Chan, \& van Aalst, 2006; Oshima et al., 2006; Scardamalia, 2002; Scardamalia \& Bereiter, 2010; Scardamalia, Bransford, Kozma, \& Quellmalz, 2012; Sun, Zhang, \& Scardamalia, 2010; Zhang, Scardamalia, Lamon, Reeve, \& Messina, 2007; Zhang, Hong, Scardamalia, Teo, \& Morley, 2011). No studies have yet been conducted to specifically look into how students perceive the role of ideas and how such perceptions relate to their knowledge-building practices.

Given the central importance of sustained idea improvement in the knowledge-building process, it is necessary to explore the quantity and quality of idea improvement activities. Moreover, it would further advance knowledge in the field of how to improve knowledge-building process with an adequate understanding of how students' idea improvement activities may be related to how they view the role of ideas for their knowledge work. It is posited that when engaged in knowledge-building practices, students would progressively become more likely to see ideas, not merely as individuals' mental constructs for the purpose of personal knowledge achievement, but as improvable objects for the purpose of community knowledge advancement.

\section{Method}

\section{Participants and context}

The participants in this elective course were 20 male and 14 female undergraduate students (age ranging from 19 to 22) from the Faculty of Education in a university in Taiwan. As Asian cultures traditionally tend to foster more didactic pedagogies, the teaching in the university at issue also tended to emphasise the importance of knowledge acquisition, as well as learning from textbook knowledge. In this particular course, however, knowledge-building pedagogy was employed as an innovative pedagogy to foster students' creative capacity for knowledge creation.

As the main theme for the course was about technology and design, the participants were required to design a technological product as the main project in this course. To this end, Knowledge Forum, a computer-supported collaborative knowledge-building environment (Scardamalia \& Bereiter, 2003), was used as an online problem-solving and discussion space for students to engage in their group knowledge work. The course lasted for 18 weeks (in a semester), which was further divided into two equal phases using midterm as a separating point in order to examine students' online performance. Throughout the 
semester, the main learning task was to solve self-identified technology problems of students' own interest by designing a new or better technology product (e.g., by redesigning a more energy-saving toilet device). To this end, they needed to generate their own ideas and then keep working on these ideas in order to tackle the target design problems; they also needed to gradually form small groups by explicitly expressing their individual interest in a certain technology problem and join a particular group. As a result, there were nine groups gradually formed with each group having 2 to 5 members $(M=3.78$; $S D=$ 1.09). Members of each group then have to collectively solve all the emerging problems related to the design of their intended technology product at issue by continually working with their ideas in the online Knowledge Forum, using additional after-class hours. Each group also has to assume collective responsibility and complete their project work independently, and the teacher did not intervene in any way into students' group work. The teacher's main role was to foster a knowledge-building environment, while students in each group needed to assume the role of knowledge workers and engage in self-initiated and self-directed group knowledge work. Through sustained work with ideas, members in each group consequently design a new product or innovate an existing one as their final group project (that is, concept only, rather than an actual product). Participants' course performance was mainly assessed based on the process of how they worked as a group online, for example, the records of online interactions such as number of notes posted, read, and built on, and the quality of their online inquiry and discussion (which was content analysed). The final technology product each group designed, however, was not graded because the main instructional goal was to foster students' high-level cognitive thinking skills. So the product was used as a scaffold to engage students in sustained thinking and working with ideas. Also, the products were only designed in concept rather than real prototypes.

\section{Fostering sustained idea improvement in the Knowledge Forum}

As a public space for ideas to exist and grow is essential from a world 3 perspective, the Knowledge Forum - an online knowledge-building environment - was employed in this study (Scardamalia \& Bereiter, 2003). While the Knowledge Forum enables computer supported collaborative learning (CSCL) - a widely recognised learning model in the field of learning sciences (Koschmann, 1996) - it is unlike most CSCL designs focusing only on collaborative learning. Instead, the Knowledge Forum has a unique focus on fostering sustained idea production and improvement as a way to fulfilling the overarching goal of community knowledge advancement. As such, the Knowledge Forum encourages community members to centre all their activities on working with their ideas (Scardamalia, 2002; Scardamalia \& Bereiter, 2003). Particularly in order to support sustained idea improvement, a set of customised scaffolds are provided in Knowledge Forum using sentence starters. These scaffolds are used to facilitate the process of idea improvement. For example, "my idea is ... " can be used to foster idea generation; "I need to understand ..." and "new information ..." can be used to support idea diversification; "this idea cannot explain..." and "a better idea is ..." can be used to facilitate idea reflection'; and "putting our ideas together...” can be used to scaffold idea integration. Overall, the first three scaffolds are more frequently used to support early-stage inquiry for the development of initial and diversified ideas, while the latter three scaffolds are used more often to facilitate deeper later-stage inquiry for the development of elaborated and more sophisticated ideas.

Figure 1 shows a sample Knowledge Forum view and a Knowledge Forum note. To elaborate, a Knowledge Forum view represents a virtual problem-solving space enabled by community members for idea-centred knowledge work. Within a Knowledge Forum view, students are able to identify a problem of inquiry and produce ideas in the form of notes to address the identified problem while using the customisable scaffolds to guide their inquiry. Progressively, an inquiry topic may emerge, and students can further improve their ideas within the topic by using all tools provided in the Knowledge Forum (e.g., using keyword tool or search tool to relate ideas). 


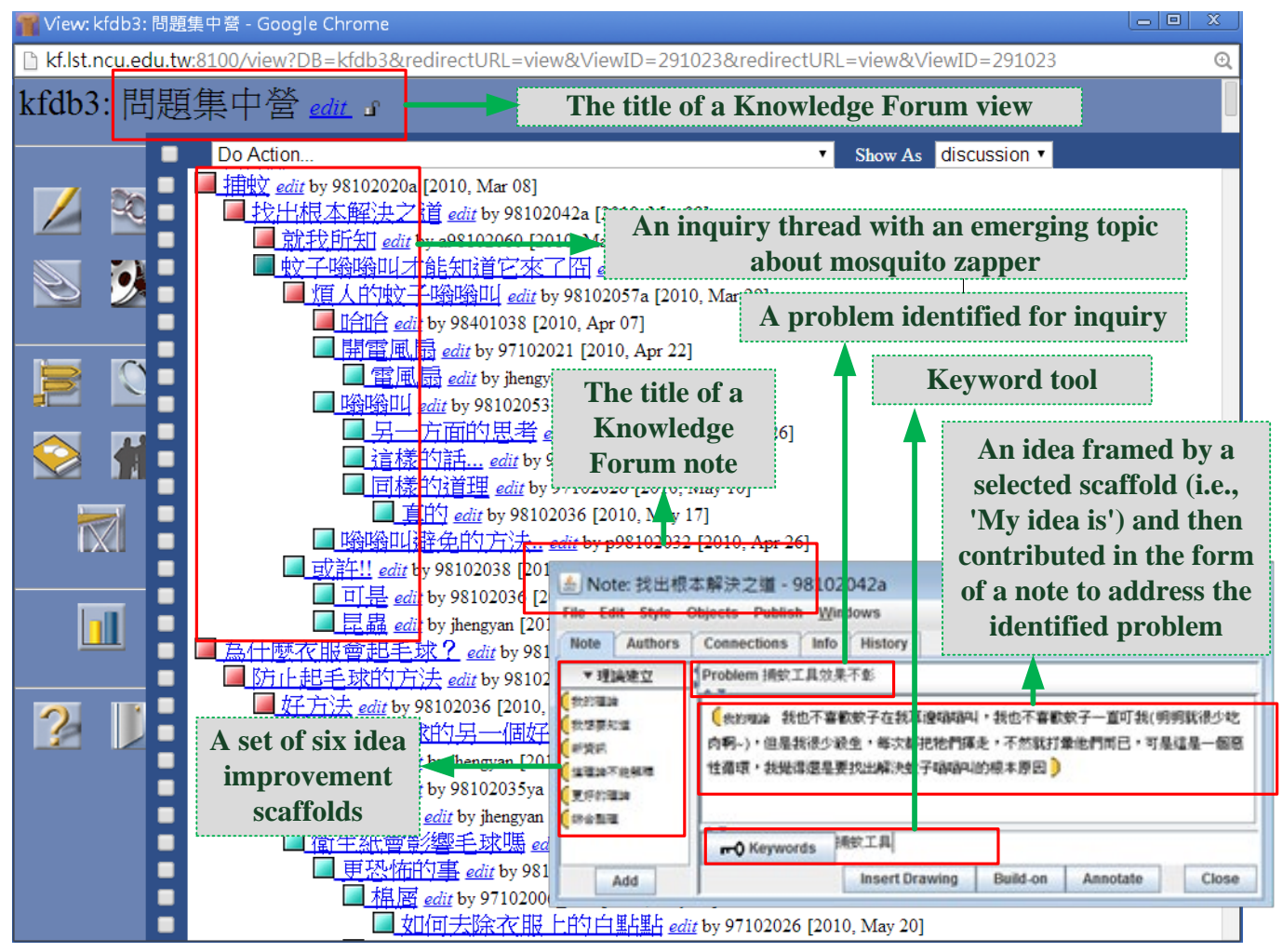

Figure 1. An illustration of a sample Knowledge Forum view and some tools (such as customisable scaffolds and keyword tools)

\section{Data sources, instruments, and data analysis}

First, descriptive analysis was employed to examine students' overall online performance, focusing on major online activities (e.g., number of notes contributed, read, and built on). Then, how students used scaffolds to work with ideas for online inquiry was assessed. Further, social network analysis (see Wasserman, \& Faust, 1994) was performed to analyse detailed online interactions, focusing on notereading and note-linking patterns, in order to examine group dynamics over time, by using the following two measures: (1) network density (defined as the proportion of note-connections in a network community relative to the total possible number of note-connections; the higher the value of a network community is, the stronger the interactions of that network community is implied); and (2) betweenness centralisation (defined as the degree of variance in a network community; the higher its value is, the higher degree of variance/decentralisation in a community is implied) (Hanneman \& Riddle, 2005).

In addition, a survey developed by the authors was used to explore change in participants' epistemic views regarding the roles of ideas for knowledge work. This survey was administered twice in the beginning and at the end of the course, using open-ended questions, including:

- What is idea?

- Where are ideas from?

- Why do we need ideas?

- What are ideas for?

- $\quad$ Can ideas be improved, and if so, how?

Table 1 shows a coding scheme that was developed based on Bereiter and Scardamalia's (2003) conceptualisation on two modes (belief vs design) of views for knowledge work as discussed earlier. The scheme was used to code student responses to the questions mentioned above (Strauss \& Corbin, 1990) Inter-coder reliability was computed as 0.90 by using kappa coefficient (as the data generated is measured in nominal scale). 
Table 1

Coding scheme regarding students' preferred mode of knowledge work: belief vs design mode

\begin{tabular}{|c|c|c|}
\hline Code & Description & Example \\
\hline $\begin{array}{l}\text { Belief-mode } \\
\text { view of ideas }\end{array}$ & $\begin{array}{l}\text { Highlighting ideas as } \\
\text { building blocks for } \\
\text { personal knowledge } \\
\text { growth; as such, ideas are } \\
\text { considered as abstract } \\
\text { thoughts residing in one’s } \\
\text { mind-as-container, as } \\
\text { one’s subjective opinions } \\
\text { or viewpoints; or as } \\
\text { products derived from } \\
\text { personal intellectual effort. }\end{array}$ & $\begin{array}{l}\text { "Ideas are my personal views towards certain things. (S1) } \\
\text { "Ideas are theories developed by myself based on my } \\
\text { standpoint.” (S6) } \\
\text { "Ideas are judgmental thinking derived from one’s human } \\
\text { brain.” (S7) } \\
\text { "Ideas are every action in our minds, including fleeting } \\
\text { thoughts, sudden flashes of inspiration, considerate decision } \\
\text {.. etc.” (S23) } \\
\text { "Ideas are refined by means of self-reflection.” (S29) }\end{array}$ \\
\hline $\begin{array}{l}\text { Design-mode } \\
\text { view of ideas }\end{array}$ & $\begin{array}{l}\text { Highlighting ideas as } \\
\text { improvable, real-life } \\
\text { objects, or public property } \\
\text { for collaborative } \\
\text { knowledge advancement; } \\
\text { or as means to solving } \\
\text { real-world problems. }\end{array}$ & $\begin{array}{l}\text { "Ideas can be modified due to the contact and influence of } \\
\text { other people.” (S1) } \\
\text { "Ideas can make our lives better and more convenient.” (S02) } \\
\text { "Ideas originate from our demands, and our needs for solving } \\
\text { problems.” (S06) } \\
\text { "Online discussion has allowed us to contribute even better } \\
\text { ideas or propose some revision comments on existing ideas to } \\
\text { make it more realistic and workable.” (S25) } \\
\text { "By means of wide discussion of group members who have } \\
\text { diverse experiences and perspectives, it is more likely to } \\
\text { identify the weaknesses of an idea and they try to improve } \\
\text { it." (S39). }\end{array}$ \\
\hline
\end{tabular}

Moreover, to evaluate the quality of ideas students worked in this study, we adopted the scales for idea evaluation developed by Dean et al. (2006). The original scales contain four main dimensions including novelty, workability, relevance, and specificity; and each dimension further contain two to three subdimensions. Using confirmatory factor analysis, the scales were tested to have high validity (e.g., the goodness of fit index was 0.95); and using two different problems for idea evaluation, the scales were also found to have high inter-rater reliability (which was greater than 0.83 among all four dimensions). In the present study, only the four main dimensions were employed to evaluate the quality of ideas. Table 2 shows the coding scheme, rating criteria, and some examples of students' ideas that were given four points based on the rating criteria. In the present study, all ideas recorded in the Knowledge Forum were evaluated against these four dimensions. The inter-rating reliability was computed to be .96 by using Spearman correlation (as the data generated is measured in ordinal scale).

Table 2

Scales of idea evaluation

\begin{tabular}{|c|c|c|}
\hline Dimension/Description & Rating criteria & Example \\
\hline $\begin{array}{l}\text { Novelty: The degree to } \\
\text { which an idea is } \\
\text { original. }\end{array}$ & $\begin{array}{l}\text { From } 1 \text { point (i.e., common, } \\
\text { mundane, boring) to } 4 \text { points (i.e., } \\
\text { not expressed before, rare, unusual, } \\
\text { and ingenious, imaginative or } \\
\text { surprising; or may be humorous). }\end{array}$ & $\begin{array}{l}\text { "When taking a bus, it would be more } \\
\text { convenient if the back of the bus chair } \\
\text { can have a small screen showing } \\
\text { information about next bus stop" (S39). }\end{array}$ \\
\hline $\begin{array}{l}\text { Workability: An idea } \\
\text { is feasible if it can be } \\
\text { easily implemented } \\
\text { and does not violate } \\
\text { known constraints. }\end{array}$ & $\begin{array}{l}\text { From } 1 \text { point (i.e., radically violates } \\
\text { laws or sensibilities or totally } \\
\text { unacceptable business practice) to } 4 \\
\text { points (i.e., common strategies that } \\
\text { violate no norms or sensibilities). }\end{array}$ & $\begin{array}{l}\text { "I plan to design correction pens that } \\
\text { have all different colors instead of just } \\
\text { white color. So not only they can be used } \\
\text { for correction purpose on various colored } \\
\text { papers, but they can be used as } \\
\text { decoration tools, too." (S23). }\end{array}$ \\
\hline $\begin{array}{l}\text { Relevance: An idea } \\
\text { applies to the stated } \\
\text { problem and will be } \\
\text { effective at solving the } \\
\text { problem. }\end{array}$ & $\begin{array}{l}\text { From } 1 \text { point (i.e., intervention is } \\
\text { not stated or does not produce a } \\
\text { useful outcome) to } 4 \text { points (i.e., } \\
\text { solves an identified problem that is } \\
\text { directly related to the stated } \\
\text { problem). }\end{array}$ & $\begin{array}{l}\text { "There are many mosquitoes in our } \\
\text { dormitory. If we can design a mosquito } \\
\text { killer that does not emit light and produce } \\
\text { buzzing noise..., I am sure people can } \\
\text { sleep even better." (S31). }\end{array}$ \\
\hline
\end{tabular}




\begin{tabular}{lll}
\hline $\begin{array}{l}\text { Specificity: An idea is } \\
\text { specific if it is clear } \\
\text { (worked out in detail). }\end{array}$ & $\begin{array}{l}\text { From 1 point (i.e., implication is not } \\
\text { stated, even though relevant) to } 4 \\
\text { points (implication is clearly stated } \\
\text { and makes sense). }\end{array}$ & $\begin{array}{l}\text { "We should design a car which shaped } \\
\text { like a ball. This way, the driver's seat can } \\
\text { rotate in all direction. So there will be no } \\
\text { need to park a car backward as the driver } \\
\text { can rotate 180 degree and then drive the } \\
\text { car forward for parking." (S14). }\end{array}$ \\
\hline
\end{tabular}

Source: Modified from Dean et al. (2006)

\section{Results}

\section{Overall analysis of online performance}

Pre-post comparisons were made between the early and later knowledge-building phases (using midterm as a separation point) for online activities (see Table 3). The rationale of using the two phases for analysis is because these two phases corresponded to the two main idea improvement activities, with the early knowledge-building phase highlighting more divergent idea-diversification activity and the later knowledge-building phase focusing on more convergent idea-elaboration activity. Overall, the frequency of all activities was quite consistent. There were no significant differences between the two phases in terms of all major online activities, except that there was a significant increase in the number of notes read in phase 2, which indicates increasing community awareness of group knowledge work (e.g., who was interacting or collaborating with whom in a group, and what ideas were being improved) towards the end of the course. Additionally, all the online measures were found significantly correlated with one another (all $r$ 's $>.43$, p's $<.05$, for all measures in phase 1; (all $r$ 's $>.31$, $p$ 's $<.05$, for all measures in phase 2; and all $r$ 's $>.60$ 's $<.01$, for all measures throughout the whole semester, e.g., see Table 4), which suggests that the more active the participants were in one type of online activity, the more likely they would be actively engaged in another type of activity.

Table 3

Online knowledge-building (KB) activities $(n=41)$

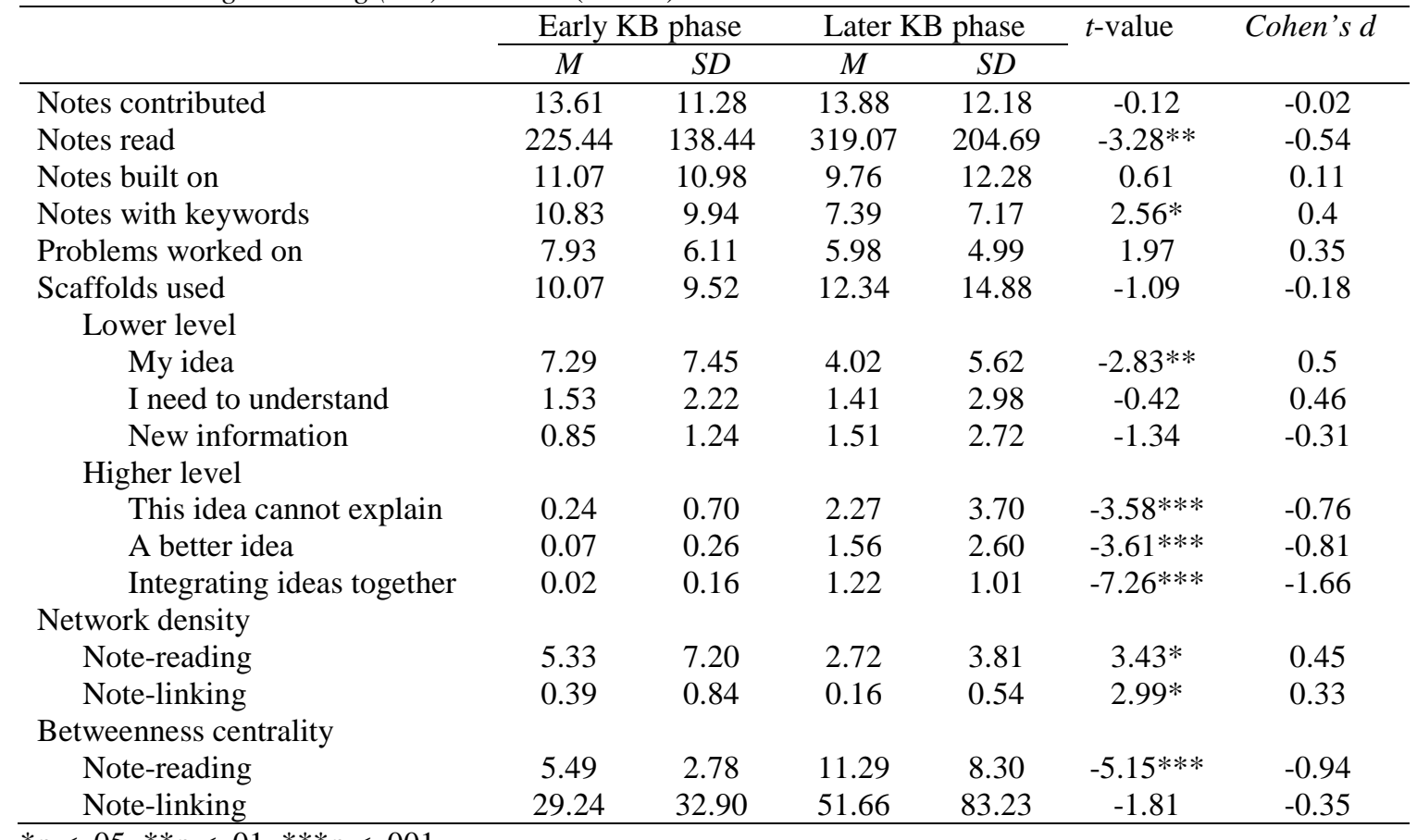


Table 4

Correlations between basic knowledge-building measures

\begin{tabular}{|c|c|c|c|c|}
\hline Basic measures & 2. & 3. & 4. & 5. \\
\hline 1. Notes created and worked & $.99 * *$ & $.60 * *$ & $.85 * *$ & $.89 * *$ \\
\hline 2. Problems worked on & . & $.81 * *$ & $.77 * *$ & $.59 * *$ \\
\hline 3. Notes built on & & . & $.89 * *$ & $.60 * *$ \\
\hline 4. Scaffold supplies & & & . & $.66^{* *}$ \\
\hline 5. Notes read & & & & \\
\hline
\end{tabular}
$* * p<.01$

More importantly, based on the comparison between the two phases, it was found that there were some changes in the use of scaffolds. For lower-level scaffolds highlighting idea generation and exchange, there was a significant decrease in use of the "My idea ..." scaffold $(t=-2.83, p<.05)$, suggesting that more diffused effort and attention for producing diversified ideas was progressively reduced and replaced by more focused inquiry. In a coherent sense, for the higher-level scaffolds that highlight idea clarification and integration, there were significant increases in all three scaffolds, indicating that the participants were gradually more able to engage in deep inquiry activities.

As a main interest of this study is collaborative knowledge building, additional analysis of interaction patterns was conducted using social network analysis. As shown in the bottom part of Table 3, overall, there was a descending trend in terms of network density from early knowledge-building to later knowledge-building phase for both note-reading and note-linking activities. Further, there was an ascending trend in terms of betweenness centrality from early to later phase (for note-reading only). To elaborate, relatively lower network density and higher betweenness centrality in the later phase implies that there were less whole community-based online activities and more focused small group-based activities. This may be because that the instructional design of this course encouraged students to progressively form groups and work within groups based on common interest in certain technology problems. Another explanation is that towards the end of the semester, within-group inquiry became more essential for completing each group's final technological product. This is also confirmed by the fact that there were progressively more idea elaboration and intensive inquiry activities within groups (as shown by the higher-level scaffold use), rather than merely idea-sharing and shallow inquiry activities within the whole community and between groups (as shown by the lower-level scaffold use). It is evident that more frequent use of higher-level scaffolds was found in later knowledge-building phase. Collectively, all these quantitative online behavioural and interactive measures indicate that students were progressively more able to focus on their collaborative group work. As an example, Figure 2 (left side) also illustrates an instance of students' online knowledge-building behaviours focusing on inquiring how to reduce the noise produced from typing the keyboard. To address this problem, for example, students discussed various ideas such as "using keyboard protection sheet to reduce noise," "writing by using touchpad instead of typing," “designing better keyboard by using new materials”. Figure 2 (right side) also shows the overall behavioural pattern of the frequent interactions among students focusing on note-built-on activities. 


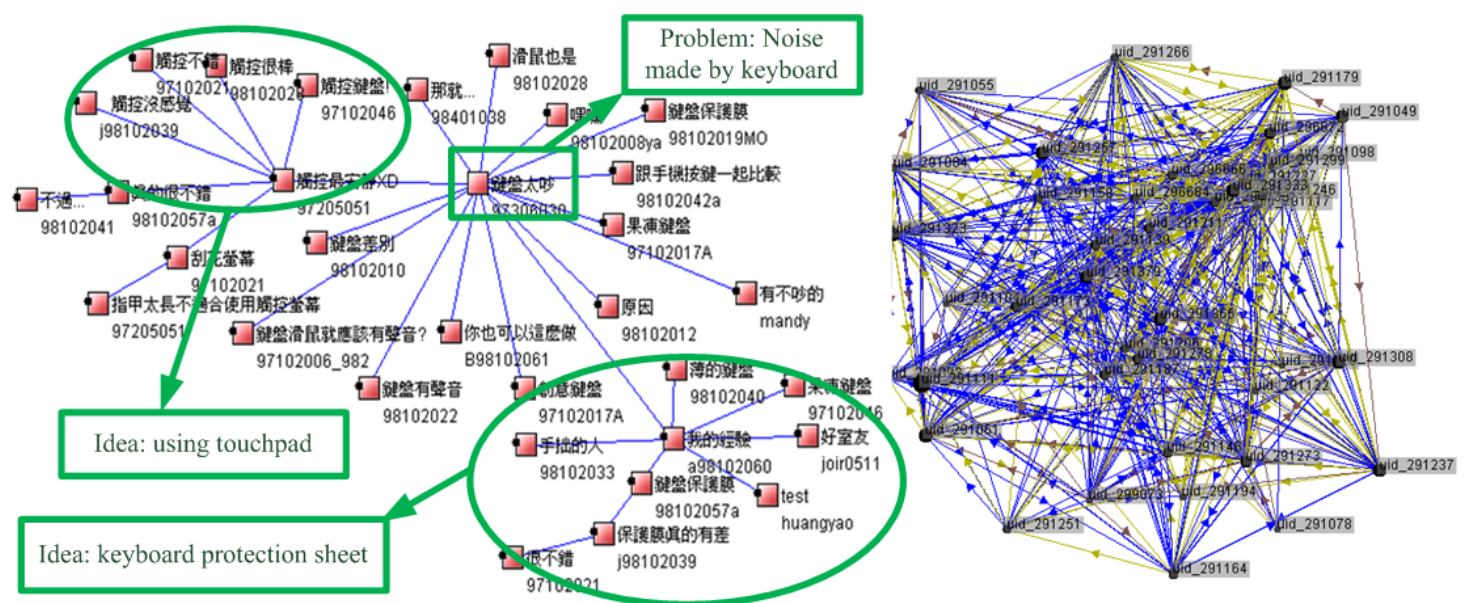

Figure 2. An instance of students' online interaction behaviours focusing on inquiring how to reduce the noise produced from typing on the keyboard (left side) and the overall pattern of interactions among students focusing on note-built-on activities

\section{Analysis of group view change and inquiry activities}

As a beginning analysis, it was found that there was a significant decrease in ratings from pre-survey ( $M$ $=1.86 ; S D=0.91)$ to post-survey $(M=1.37 ; S D=0.92)$ in terms of a belief-mode view of ideas $(t=-2.39$, $p<.05)$. Students were able to progressively place less emphasis on treating ideas as merely abstract thoughts, opinions, viewpoints, or mental constructs (residing in one's mind-as-container) for the purpose of facilitating individual knowledge work (i.e., personal knowledge growth and accumulation). On the other hand, it was found that there was a significant increase $(t=2.39, p<.001)$ from pre-survey $(M=$ 2.20; $S D=1.40)$ to post-survey $(M=5.00 ; S D=1.00)$ in terms of a design-mode view of ideas in that students were progressively more able to also view ideas as concrete, real-life objects, or public properties to be collaboratively shared and improved for the purpose of advancing community or group knowledge. The findings suggest that through frequent online interactions and open discussion in the Knowledge Forum to work with (e.g., diversifying, clarifying, and improving) ideas, students were more likely to use ideas for design-mode, knowledge-creating work than for belief-mode, knowledgeaccumulating work. As this study is mainly concerned with group work, one of the next relevant questions to ask is whether there is also difference in terms of change of epistemic views between groups and whether such view change is associated with students’ online group inquiry activities.

Student groups in this course were formed based on individual interest in certain technology problems. To investigate the general difference in view change between groups, a view-change score of each group was first computed, by averaging individual students' scores in each group. Then, all groups were further divided into high-change group ( $n=5$ groups, with each group containing $5,3,3,2,5$ members respectively) and low-change groups ( $n=4$ groups, with each group containing 5, 4, 4, 3 member respectively), using the average score of view change $(M=4.88, S D=2.51)$ of all groups as a separation point. As a baseline comparison (see Table 5), it was found that there was a significant difference in terms of groups' view-change scores $(\mathrm{F}=9.72$, $\mathrm{p}<.05)$ between the high-change groups $(M=6.61, S D=2.09)$ and the low-change groups $(M=2.79, S D=1.38)$. Moreover, when comparing basic online measures, it was also found that high-change groups tended to spend more time (in weeks) for online group discussion $(M=6.00 ; S D=4.18)$ than the low-change groups $(M=4.50, S D=3.00)$. Similarly, the high-change groups also posted more notes to Knowledge Forum $(M=31.2 ; S D=17.16)$ than the low-change groups $(M=23.25, S D=24.07)$. But the results were not statistically significantly. This implies that the quantity of inquiry time and note contribution did not really play a key role in groups’ view change.

A further investigation on group activity by looking into the quality of ideas recorded during their online inquiry was conducted. In particular, using Dean et al.'s (2006) four scales of idea evaluation (see Table 2 above), each note was assessed and given a score. As shown in Table 5, the scores between the two groupings (i.e. high-change and low-change groups) for an overall comparison (all four dimensions combined) were significantly different $(F=10.535, p<.01)$; and in terms of more specific comparisons, 
it was found that there was no significant difference between the two groupings in terms of the novelty dimension $(F=2.49, p>.05)$ and the specificity dimension $(F=0.17, p>.05)$. The reason why improvement was not significant in the novelty dimension may be that novelty effect gradually wore off with students over the long period of inquiry in a whole semester. Alternatively, it may be because students were lack of real work experiences to improve the novelty and specificity of ideas to a significant level. Nevertheless, it was found that there were significant differences between the two groupings in terms of the workability dimension $(F=4.97, p<.05)$ and the relevance dimension $(F=$ 7.97, $p<.01)$. Students with high view-change were more likely to work out on the practicality of their ideas (workability) and also to identify connections among all ideas they were working with (relevance). To triangulate the findings, it was further found that there were relationships between groups' epistemic views and the quality of groups' idea improvement activities in these two particular dimensions $(\rho=.45$, $p<.01$ for workability; and $\rho=.33, p<.01$ for relevance), suggesting that online inquiry activities were somewhat related to the quality of idea improvement in group.

Table 5

Comparison between high-change and low-change groups for view change, quality of ideas $(n=41)$

\begin{tabular}{|c|c|c|c|c|c|c|}
\hline & \multicolumn{2}{|c|}{$\begin{array}{l}\text { High-change groups } \\
\text { ( } n=5 \text { groups) }\end{array}$} & \multicolumn{2}{|c|}{$\begin{array}{l}\text { Low-change groups } \\
\text { ( } n=4 \text { groups) }\end{array}$} & \multirow[t]{2}{*}{$F$ value } & \multirow[t]{2}{*}{ Cohen's d } \\
\hline & $M$ & $S D$ & $M$ & $S D$ & & \\
\hline \multicolumn{7}{|l|}{ Baseline analysis } \\
\hline View change & 6.61 & 2.09 & 2.79 & 1.38 & $9.72 *$ & 2.18 \\
\hline Notes contributed & 31.20 & 17.16 & 23.25 & 24.07 & 0.34 & 0.38 \\
\hline $\begin{array}{l}\text { Duration of discussion } \\
\text { (weeks) }\end{array}$ & 6 & 4.18 & 4.5 & 3 & 0.36 & 0.41 \\
\hline \multicolumn{7}{|l|}{ Dimension of idea evaluation } \\
\hline All dimensions combined & 10.81 & 0.93 & 9.97 & 0.90 & $10.54 * *$ & 0.92 \\
\hline Novelty & 2.69 & 0.11 & 2.79 & 0.52 & 0.67 & -0.27 \\
\hline Workability & 3.00 & 0.33 & 2.51 & 0.17 & $29.41^{* * *}$ & 1.87 \\
\hline Relevance & 2.88 & 0.22 & 2.50 & 0.13 & $38.55^{* * *}$ & 2.1 \\
\hline Specificity & 2.24 & 0.27 & 2.17 & 0.08 & 1.06 & 0.35 \\
\hline
\end{tabular}

$* p<.05 * * p<.01 * * * p<.001$

\section{Discussion}

In summary, the findings in this study indicate that engaging students in knowledge building was effective in enhancing students' online collaborative and inquiry performance. First, in response to the first research question, it was found that the participants' online performance was consistently active throughout the whole semester. This is perhaps because pedagogically they were allowed to solve authentic real-world problems based on their learning interest and were also encouraged to continually improve their ideas for addressing those technology problems at issue; therefore, it is more likely that they maintained their online inquiry interest in a sustained and self-directed manner. Also, students were more willing and able to work cohesively as groups to engage in higher level inquiry activity that supported their collaborative knowledge work. Second, in response to the second research question, the participants were able to develop a more design-mode view that sees ideas as improvable objects for collaborative knowledge construction, rather than just viewing them as abstract thoughts for mere personal knowledge growth and accumulation. Also, it was found that there were some significant relationships between the groups' changed views of the role of ideas for more creative knowledge work and the overall quality of ideas being collectively improved in groups. In general, groups who perceived the role of ideas as concrete, real-world objects for knowledge innovation from a design-mode view tended to produce more quality ideas (especially in terms of the workability and relevance of ideas). In contrast, groups who perceived the role of ideas as mere building blocks for personal knowledge acquisition from a belief-mode view tended to produce ideas with relatively less quality. A major reason why students were able to change their epistemic views towards the role of ideas may have to do with the instructional approach employed in this course, which encouraged students to initially explore divergent ideas and then progressively move further to engage in convergent idea improvement activity. 
In conclusion, our study suggests that it is possible to transform a traditionally more teacher-centred learning environment into a more constructivist-oriented knowledge-building environment in a university setting. This is important, as in a highly teacher-centric learning environment, learning is only an individualistic effort and the goal for study is usually to pursue personal knowledge growth and accumulation. As such, the knowledge to be learned is strongly associated with the existing body of knowledge that is often predefined in curriculum guidelines. However, in a constructivist-oriented knowledge-building environment, learners are given the opportunity to assume the role of knowledge workers who need to collaborate as a group to advance their collective understanding of a topic inquired. As such, knowledge is actively pursued through the production and development of ideas (as the tentative knowledge claims) that are being continuously improved by learners who act as knowledge collaborators within a given group or community. As our society is progressively more reliant on a knowledge economy, the challenge for all knowledge-driven organisations is sustained knowledge creation. Our education thus needs to cultivate among students the required creative competencies in order for them to transform ideas into more powerful, coherent, and feasible solutions, products, or theories and to make our society a better place to live (Scardamalia \& Bereiter, 2003). To this end, students also need to develop a more constructive or creative view that sees ideas as real-world, improvable objects for the advancement of public knowledge.

Admittedly, there are limitations in this study. First, given the qualitative nature of the study design and the tool it is based around, it is acknowledged that generalisability and predictability need to be taken into consideration when interpreting the study outcomes. Although insights derived from analysis of a single course may still be generalisable in similar contexts (e.g., Cobb, 2001), further studies in more diverse class contexts are necessary in order to provide more convincing evidence. Second, while pre-post epistemic view change was found to relate to the quality of ideas during online inquiry, as the relationships were not very strong, it would be helpful to further examine how other more detailed intervening factors (e.g., the requirement to produce group outcome, peer interaction, and the degree of group engagement) might affect the post-survey responses in relation to view change. It would also be useful to conduct more qualitative studies using alternative methods (e.g., in-depth interview) to further triangulate the findings and provide a fuller picture of how the students actually function in a knowledgebuilding environment. Doing so would also help deepen our understanding of the relationships between students' group performance and their epistemic views of ideas. Third, the findings derived from this study were based on data gathered from students' inquiry activity in an online learning environment and thus were not generalisable to face-to-face discussion settings. Further studies may be conducted in faceto-face learning environments to see whether the same results can be replicated using the same knowledge-building approach. Fourth, another issue is whether the epistemic change identified among students in this study is likely to persist. It would be useful if a follow-up longitudinal study could be conducted in order to answer this question. Finally, the present study was situated in an Asian cultural context where the teaching pedagogies tend to be more didactic-oriented; it would be beneficial if readers interpret the findings with some sociocultural understanding of the Asian countries in mind.

\section{Acknowledgements}

Support for writing this article was provided from Taiwan Ministry of Science and Technology grants NSC\#101-2628-S-004-001-MY3, \& MOST\#104-2511-S-004 -001 -MY3.

\section{References}

Adams, G.L., \& Engelmann, S. (1996). Research on direct instruction: 25 years beyond DISTAR. Seattle: Educational Achievement Systems.

Bereiter, C. (1994). Constructivism, socioculturalism, and Popper's world 3. Educational Researcher, 23(7), 21-23. doi:10.2307/1176935

Bereiter, C. (2002). Education and mind in the knowledge age. Mahwah, NJ: Erlbaum.

Bereiter, C., \& Scardamalia, M. (2003). Learning to work creatively with knowledge. In E. D. Corte, L. Verschaffel, N. Entwistle \& J. V. Merrienboer (Eds.), Unravelling basic components and dimensions of powerful learning environments (pp. 55-68). Oxford: Elsevier Science.

Brown, T. (2009). Change by design: How design thinking transforms organizations and inspires innovation. New York, NY: HarperCollins.

Chen, B., Chuy, M., Resendes, M., Scardamalia, M., \& Bereiter, C. (2011). Evaluation by Grade 5 and 6 students of the promisingness of ideas in knowledge-building discourse. In S. Spada, G. Stahl, N. 
Miyake, \& N. Law (Eds.), Connecting Computer-Supported Collaborative Learning to Policy and Practice: CSCL2011 Conference Proceedings (Vol. 2, pp. 571-575). International Society of the Learning Sciences.

Chen, B., Scardamalia, M., Acosta, A., Resendes, M., \& Kici, D. (2013). Promisingness judgments as facilitators of knowledge building. In N. Rummel, M. Kapur, N. Nathan, \& S. Puntambekar (Eds.), To See the World and a Grain of Sand: Learning across Levels of Space, Time, and Scale: CSCL 2013 Conference Proceedings (Vol. 2, pp. 231-232). International Society of the Learning Sciences.

Cobb, P. (2001). Supporting the improvement of learning and teaching in social and institutional context. In S. Carver \& D. Klahr (Eds.), Cognition and instruction: Twenty-five years of progress (pp. 455478). Mahwah, NJ: Erlbaum.

Connolly, T., Jessup L. M., \& Valacich J. S. (1990). Effects of anonymity and evaluative tone on Idea generation in computer-mediated groups. Management Science, 36(6), 689-703. doi:0.1287/mnsc.36.6.689

Cross, N. (2007). Designerly ways of knowing. Boston, MA: Birkhauser.

Dean, D. L., Hender J. M., Rodgers T. L., \& Santanen, E. L. (2006). Identifying quality, novel, and creative ideas: Constructs and scales for idea evaluation. Journal of the Association for Information Systems, 7(10), 646-698. Retrieved from http://aisel.aisnet.org/jais/vol7/iss10/30

Dehler, J., Bodemer, D., Buder, J., \& Hesse, F. W. (2011). Guiding knowledge communication in CSCL via group knowledge awareness. Computers in Human Behavior, 27(3), 1068-1078. doi:10.1016/j.chb.2010.05.018

Faure, C. (2004). Beyond Brainstorming: The Effects of Different Group Procedures on Selection of Ideas and Satisfaction with the Process. Journal of Creative Behavior, 38(1), 13-34. doi:10.1002/j.2162-6057.2004.tb01229.x

Florida, R. L. (2002). The rise of the creative class: and how it's transforming work, leisure, community and everyday life. New York, NY: Basic Books.

Fuller, S. (1988). Social epistemology. Bloomington: Indiana University Press.

Gong, Y., Kim, T. Y., Zhu, J., \& Lee, D. R. (2013). A multilevel model of team goal orientation, information exchange, and creativity. Academy of Management Journal, 56, 827-851. doi:10.5465/amj.2011.0177

Goos, M., Galbraith, P., \& Renshaw, P. (2002). Socially mediated metacognition: Creating collaborative zones of proximal development in small group problem solving. Educational studies in Mathematics, 49(2), 193-223. doi:10.1023/A:1016209010120

Graham, W. K. (1977). Acceptance of ideas generated through individual and group brainstorming. Journal of Social Psychology, 101, 231-234. doi:10.1080/00224545.1977.9924013

Hanneman, R. E., \& Riddle, M. (2005). Introduction to social network methods. Riverside: University of California. Retrieved from http://faculty.ucr.edu/ hanneman/

Hargreaves, D. H. (1999). The knowledge-creating school. British Journal of Educational Studies, 47(2), 122-144. doi:10.1111/1467-8527.00107

Hong, H. Y., Chai, C. S., \& Tsai, C. C. (2015). College students constructing collective knowledge of natural science history in a collaborative knowledge building community. Journal of Science Education and Technology, 1-13. doi:10.1007/s10956-015-9546-8

Hong, H.-Y., Chang, Y.-H. \& Chai, C. S. (2014). Fostering a collaborative and creative climate in a college class through idea-centered knowledge-building. Instructional Science, 42(3), 389-407. doi:10.1007/s11251-013-9289-y

Hong, H.-Y. \& Scardamalia, M. (2014). Community knowledge assessment in a knowledge building environment. Computers \& Education, 71, 279-288. doi:10.1016/j.compedu.2013.09.009

Hong, H.-Y., \& Sullivan, F. R. (2009). Towards an idea-centered, principle-based design approach to support learning as knowledge creation. Educational Technology Research \& Development, 57(5), 613-627. doi:10.1007/s11423-009-9122-0

Kipp, P., Bittner, E., Bretschneider, U., \& Marco, J. (2014). Collaborative elaboration of early innovation ideas. i-com, 13(2), 20-25. doi:10.1515/icom-2014-0016

Kohn, N. W., Paulus, P. B., \& Choi, Y. (2011). Building on the ideas of others: An examination of the idea combination process. Journal of Experimental Social Psychology, 47(3), 554-561. doi:10.1016/j.jesp.2011.01.004

Koschmann, T. (1996). Computer supported collaborative learning: theory and practice of an emerging paradigm. Mahwah, NJ: Erlbaum.

Kudrowitz, B. M., \& Wallace, D. (2013). Assessing the quality of ideas from prolific, early-stage product ideation. Journal of Engineering Design, 24(2), 120-139. doi:10.1080/09544828.2012.676633 
Lee, E. Y., Chan, C. K., \& van Aalst, J. (2006). Students assessing their own collaborative knowledge building. International Journal of Computer-Supported Collaborative Learning, 1(1), 57-87. doi:10.1007/s11412-006-6844-4

Linsey, J. S., Clauss, E. F., Kurtoglu, T., Murphy, J. T., Wood, K. L., \& Markman, A. B. (2011). An experimental study of group idea generation techniques: understanding the roles of idea representation and viewing methods. Journal of Mechanical Design, 133(3), 031008-031015. doi:10.1115/1.4003498

MacCrimmon, K. R., \& Wagner, C. (1994). Stimulating ideas through creativity software. Management Science, 40(11), 1514-1532. doi:10.1007/BF02504684

Magliaro, S. G., Lockee, B. B., \& Burton, J. K. (2005). Direct instruction revisited: A key model for instructional technology. Educational Technology Research and Development, 53(4), 41-55.

Miura, A. \& Hida, M. (2004). Synergy between diversity and similarity in group idea generation. Small Group Research, 35(5), 540-564. doi:10.1177/1046496404264942

Mumford, M. D. (2001). Tradeoffs between ideas and structure: individual versus group performance in creative problem solving. Journal of Creative Behavior, 35(1), 1-23. doi:10.1002/j.21626057.2001.tb01218.x

Osborn, A. F. (1953) Applied imagination (1st ed.). New York, NY: Scribner.

Oshima, J., Oshima, R., Murayama, I., Inagaki, S., Takenaka, M., Yamamoto, T., Yamaguchi, Y., \& Nakayama, H. (2006). Knowledge-building activity structures in Japanese elementary science pedagogy. International Journal of Computer-Supported Collaborative Learning, 1(2), 229-246. doi:10.1007/s11412-006-8995-8

Papert, S. (2000). What's the big idea: Towards a pedagogy of idea power. IBM Systems Journal, 39(3-4), 720-729. doi:10.1147/sj.393.0720

Paulus, B. P., \& Yang, H.-C. (2000). Idea generation in groups: A basis for creativity in organizations. Organizational Behavior and Human Decision Processes, 82(1), 76-87. doi:10.1006/obhd.2000.2888

Perttula, M. K., Krause, C. M., \& Sipilä, P. (2006). Does idea exchange promote productivity in design idea generation?. CoDesign, 2(3), 125-138. doi:10.1080/15710880600797942

Popper, K. R. (1972). Objective knowledge: An evolutionary approach. Oxford: Clarendon Press.

Popper, K. (1978, April). Three worlds. Paper presented at the Tanner Lecture on Human Values, University of Michigan. Retrieved from http://tannerlectures.utah.edu/_documents/a-toz/p/popper80.pdf

Reigeluth, C. M. (Ed.). (2013). Instructional-design theories and models: A new paradigm of instructional theory (Vol. 2). Oxford: Routledge.

Rietzschel, E. F., Nijstad, B. A., \& Stroebe, W. (2014). Effects of problem scope and creativity instructions on idea generation and selection. Creativity Research Journal, 26(2), 185-191. doi:10.1080/10400419.2014.901084

Scardamalia, M. (2002). Collective cognitive responsibility for the advancement of knowledge. In B. Smith (Ed.). Liberal education in a knowledge society (pp. 67-98). Chicago, IL: Open Court.

Scardamalia, M., \& Bereiter, C. (2003). Beyond brainstorming: Sustained creative work with ideas. Retrieved from http://ikit.org/fulltext/2003BeyondBrainstorming.html

Scardamalia, M., \& Bereiter, C. (2006). Knowledge building: Theory, pedagogy, and technology. In K. Sawyer (Ed.), Cambridge handbook of the learning sciences, (pp. 97-118). New York, NY: Cambridge University Press.

Scardamalia, M., \& Bereiter, C. (2010). A brief history of knowledge building. Canadian Journal of Learning and Technology, 36(1). Retrieved from http://www.cjlt.ca/index.php/cjlt/article/view/579

Scardamalia, M., Bransford, J., Kozma, B., \& Quellmalz, E. (2012). New assessments and environments for knowledge building. In P. Griffin, B. McGraw, \& E. Care (Eds.), Assessment and teaching of 21st century skills (pp. 231-300). Dordrecht: Springer.

Stark, L. J., \& Perfect, T. J. (2008). The effects of repeated idea elaboration on unconscious plagiarism. Memory \& cognition, 36(1), 65-73. doi:10.3758/MC.36.1.65

Strauss, A. L., \& Corbin, J. (1990). Basics of qualitative research: Grounded theory procedures and techniques. Newbury Park, CA: Sage.

Sun, Y., Zhang, J., \& Scardamalia, M. (2010). Knowledge building and vocabulary growth over two years, Grades 3 and 4. Instructional Science, 38(2), 147-171. doi:10.1007/s11251-008-9082-5

UNESCO. (2005). Towards knowledge societies. New York, NY: Author.

Verhaegen, P. A., Vandevenne, D., Peeters, J., \& Duflou, J. R. (2013). Refinements to the variety metric for idea evaluation. Design Studies, 34(2), 243-263. doi:10.1016/j.destud.2012.08.003 
Wasserman, S., \& Faust, K. (1994). Social network analysis: Methods and applications. Cambridge: Cambridge University Press.

Zhang, J., Hong, H.-Y., Scardamalia, M., Teo, C. L., \& Morley, E. A. (2011). Sustaining knowledge building as a principle-based innovation at an elementary school. Journal of the Learning Sciences, 20(2), 262-307. doi:10.1080/10508406.2011.528317

Zhang, J., Scardamalia, M., Lamon, M., Messina, R., \& Reeve, R. (2007). Socio-cognitive dynamics of knowledge building in the work of 9-and 10-year-olds. Educational Technology Research and Development, 55(2), 117-145. doi:10.1007/s11423-006-9019-0

Corresponding author: Huang-Yao Hong, hyhong@nccu.edu.tw

Australasian Journal of Educational Technology (c) 2016.

Please cite as: Hong, H-Y., \& Chiu C-H. (2016). Understanding how students perceive the role of ideas for their knowledge work in a knowledge-building environment. Australasian Journal of Educational Technology, 32(1), 32-46. 